Article

\title{
Numerical Analysis of the Bending Properties of Cathay Poplar Glulam
}

\author{
Ying Gao ${ }^{1,2,3, *}$, Yuxuan $\mathrm{Wu}^{1,2,3}$, Xudong Zhu ${ }^{1,2,3}$, Lei Zhu ${ }^{4}$, Zhiming $\mathrm{Yu}^{1,2,3}$ and Yong $\mathrm{Wu}^{5}$
}

Received: 11 June 2015 ; Accepted: 28 September 2015 ; Published: 19 October 2015

Academic Editor: Mark Whittaker

1 MOE Key Laboratory of Wooden Material Science and Application, Beijing Forestry University,

Beijing 100083, China; wuyuxuanwood@gmail.com (Y.W.); zhuxudong5008@gmail.com (X.Z.);

yuzhiming@bjfu.edu.cn (Z.Y.)

2 Beijing Key Laboratory of Wood Science and Engineering, Beijing Forestry University, Beijing 100083, China

3 MOE Engineering Research Center of Forestry Biomass Materials and Bioenergy, Beijing Forestry University, Beijing 100083, China

4 Beijing University of Civil Engineering and Architecture, Beijing 100044, China; zhulei@bucea.edu.cn

5 Suzhou Grownhomes Co., Ltd., Suzhou 215105, China; wu.yong@crownhomes.cn

* Correspondence: gaoying@bjfu.edu.cn; Tel.: +86-151-1002-8696; Fax: +86-10-6233-8358

\begin{abstract}
This paper presents the formulae and finite element analysis models for predicting the Modulus of Elastic (MOE) and Modulus of Rupture (MOR) of Cathay poplar finger-jointed glulam. The formula of the MOE predicts the MOE of Cathay poplar glulam glued with one-component polyurethane precisely. Three formulae are used to predict the MOR, and Equation (12) predicts the MOR of Cathay poplar glulam precisely. The finite element analysis simulation results of both the MOE and MOR are similar to the experimental results. The predicted results of the finite element analysis are shown to be more accurate than those of the formulae, because the finite element analysis considers the glue layers, but the formulae do not. Three types of typical failure modes due to bending were summarized. The bending properties of Cathay poplar glulam were compared to those of Douglas fir glulam. The results show that Cathay poplar glulam has a lower stiffness, but a marginally higher strength. One-component polyurethane adhesive is shown to be more effective than resorcinol formaldehyde resin adhesive for Cathay poplar glulam. This study shows that Cathay poplar has the potential to be a glulam material in China.
\end{abstract}

Keywords: structural glued-laminated timber (glulam); Chinese domestic Cathay poplar; mechanical tests; bending properties; checking calculation; formulae; finite element analysis

\section{Introduction}

Modern wooden structures have been used in many areas around the world. Glued-laminated timber (glulam) is a type of engineered wood product that can preserve the natural beauty of the source wood during construction [1,2]. Structural glulam has been widely used in Japan, North America and Europe [3], but Chinese domestic wood species are rarely used in the construction of structural glulam manufactured in China. It is thus important to study Chinese domestic wood species that could be applicable for use in structural glulam.

Cathay poplar (Populus cathayana) is one of the most abundant, fast-growing species in northern China and is cold resistant, fast growing, straight grained, medium and evenly textured and easy to manufacture. Cathay poplar is thus an excellent material for construction components $[4,5]$.

Finite element analysis (FEA) is an efficient research method used in the wooden materials field. By establishing a finite element analysis model and post-processing, visual predictions can 
be obtained without specimen failures. In 1980, Foschi and Barrett put forward the Foschi-Barrett simulation model, which used the Monte Carlo method, to predict the Modulus of Rupture (MOR) of glulam. The Ala Tabiei [6] model simulated the nonlinearity of wood, and the Moses D.M. [7] model predicted the nonlinear deformation and brittle fracture of wood composite material. The Serrano [8] model is also a three-dimensional nonlinear FEA model, which predicted the properties of the glue layer, the size effect and tensile fracture properties when the wood was connected with bolts. Gao [9] proposed the FEA model of the deformation of timber-framed plywood panel dome structures, and the simulated results were found to be in good agreement with the results of the experiments under similar loading conditions. Frese [10-12] simulated the bending and tensile strengths of spruce and beech glulam. Qiu [13] simulated the crack propagation behavior of Chinese larch, and the numerical results correlated well with the experimental results. Based on the stiffness profile of each board and its location within the glulam, Kandler [14] established a numerical finite element model, which is able to predict the effective glulam stiffness with high accuracy.

The formula model is also commonly used to make numerical simulation of glulam. Kohler [15], Fink [16,17] and Jockwer [18-20] have published contributions about the formula model. Kohler presented a probabilistic approach for modelling the tensile strength and tensile stiffness properties of timber boards and finger joint connections of knot clusters based on the results of the experimental investigation. Fink presented a probabilistic approach for modelling the load-bearing capacity, the bending stiffness and the failure modes of glulam. In Jockwer's research, the prediction of the load-carrying capacity of notched beams was developed based on experiments and theory, and the load at initial cracking of the reinforced notches tested can be predicted with the model. Besides, the impact of knots and grain deviations on the fracture perpendicular to the grain of timber is analyzed by means of numerical models.

The Modulus of Rupture (MOE) and MOR are both paramount properties of glulam. Four formulae were derived, and finite element analysis models were established to predict the MOE and MOR of Cathay poplar finger-jointed glulam. In addition, the bending properties of Cathay poplar glulam were examined and compared to those of Douglas fir glulam. A comparison of the test and simulation results was also performed.

\section{Materials and Methods}

\subsection{Material Properties}

Cathay poplar was obtained from the Beijing Longshun Wood Market, Beijing, China. Douglas fir was imported from North America (Can-Coast Development Corp, Vancouver, BC, Canada). The moisture content of the Cathay poplar and the Douglas fir ranged from $9 \%$ to $12 \%$. The physical and mechanical properties of the Cathay poplar and Douglas fir lumber are shown in Table 1. Resorcinol formaldehyde resin adhesive (RF, Prefere 5837W, Dynea, Gaoyao, Guangdong, China) and one-component polyurethane adhesive (PU, HB S309, Purbond, Shanghai, China) were used to manufacture the glulam specimen. The resin content of RF and PU is $100 \%$ and $45 \%$ 75\%, respectively; the curing time of RF and PU is $75 \mathrm{~min}$ and $60 \mathrm{~min}$, respectively.

Table 1. Mean physical and mechanical properties of the lumber investigated in this study.

\begin{tabular}{|c|c|c|c|c|c|}
\hline Species & Thickness (mm) & Lumbers Grades & $\begin{array}{c}\text { Density } \\
\left(\mathrm{kg} \cdot \mathrm{m}^{-3}\right)\end{array}$ & $\begin{array}{c}\text { Moisture } \\
\text { Content (\%) }\end{array}$ & MOE (MPa) \\
\hline \multirow{6}{*}{ Cathay poplar } & \multirow{3}{*}{20} & $\mathrm{I}$ & 536 & 10.7 & 12,798 \\
\hline & & II & 536 & 10.7 & 11,357 \\
\hline & & III & 536 & 10.7 & 9,900 \\
\hline & \multirow{3}{*}{30} & $\mathrm{I}$ & 536 & 10.7 & 11,750 \\
\hline & & II & 536 & 10.7 & 11,297 \\
\hline & & III & 536 & 10.7 & 10,430 \\
\hline \multirow{2}{*}{ Douglas fir } & 20 & II & 498 & 9.2 & 12,500 \\
\hline & 30 & II & 498 & 9.2 & 12,236 \\
\hline
\end{tabular}




\subsection{Grading of Sawn Lumber}

Visual grading and the MOE test method were used in this study. A total of 52 pieces of Cathay poplar sawn lumbers with dimensions of 60 (width (W)) $\mathrm{mm} \times 800$ (length (L)) $\mathrm{mm}$ was tested, where half of the pieces were $20 \mathrm{~mm}$ thick and the other half were $30 \mathrm{~mm}$ thick. The lumber was graded based on GB/T (Recommended National Standards of China) 26899-2011 [21]. The concentrated knot's diameter ratio (CKDR, the ratio of the diameters of all knots to the lumbers' width in a 150 mm-long range) of Grades I, II and III lumber is not more than $20 \%, 30 \%$ and $40 \%$, respectively.

Figure 1 shows that the MOE decreases as the ratio increases. When the ratio is less than $30 \%$, the MOE of the $20 \mathrm{~mm}$-thick lumber is higher than that of the $30 \mathrm{~mm}$-thick (T) lumber. However, when the ratio is in the range of $30 \% \sim 40 \%$, the linear fit of the MOE of the $30 \mathrm{~mm}$-thick lumber is higher than that of the $20 \mathrm{~mm}$-thick lumber.

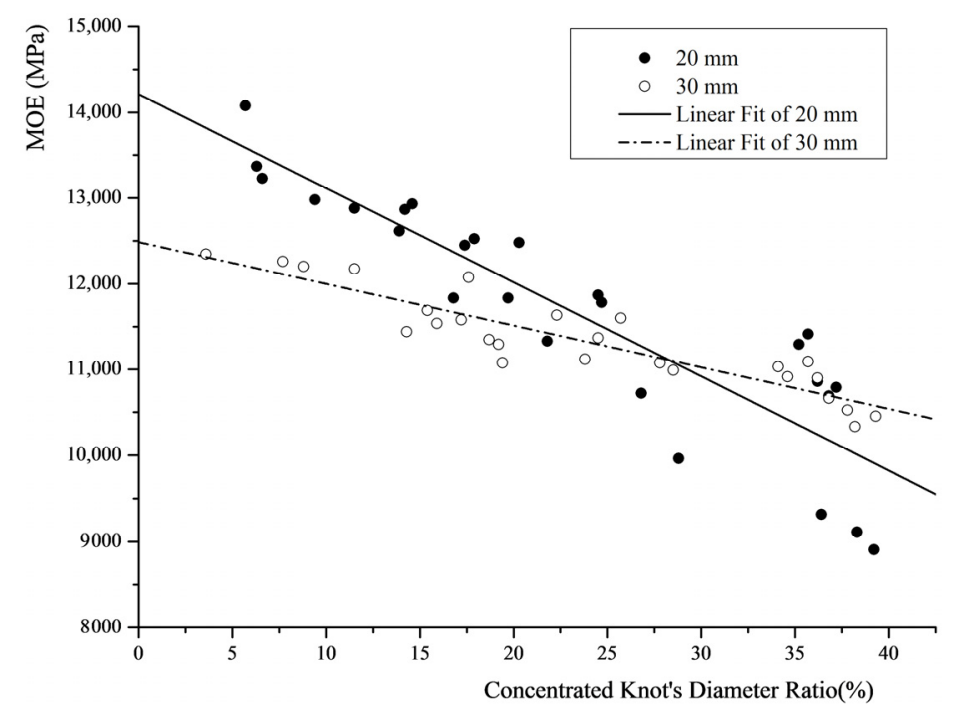

Figure 1. MOE of sawn lumber versus the concentrated knot's diameter ratio.

\subsection{Manufacturer of Specimen}

Glulam specimens were manufactured based on GB/T 26899-2011. All of the glulam specimens were $3000(\mathrm{~L}) \mathrm{mm} \times 60(\mathrm{~W}) \mathrm{mm} \times 120(\mathrm{~T}) \mathrm{mm}$. The length of finger joints was $21.5 \mathrm{~mm}$, and the width was $8.0 \mathrm{~mm}$. The distribution of finger joints in glulam satisfies the construction requirement of glulam. The positions of finger joints were at least $30 \mathrm{~cm}$ away from each adjacent layer.

The specimen parameters are shown in Table 2. To improve the bending strength of glulam [22], Grades I and II lumber were placed on the outermost layers of the 4-layer glulam and the outermost and outer layers of the 6-layer glulam. Grade III lumber was placed on the inner layers (Figure 2).

Table 2. Specimen parameters. RF, resorcinol formaldehyde; PU, polyurethane; W, width; T, thickness.

\begin{tabular}{cccccc}
\hline Species & Adhesive & $\begin{array}{c}\text { Sectional Dimensions } \\
\text { of Laminates }(\mathbf{m m})\end{array}$ & Layers & Abbreviation & Sample Size \\
\hline Cathay & RF & $60(\mathrm{~W}) \times 30(\mathrm{~T})$ & 4 & PR4 & 3 \\
poplar & RF & $60(\mathrm{~W}) \times 20(\mathrm{~T})$ & 6 & PR6 & 3 \\
\hline Douglas & PU & $60(\mathrm{~W}) \times 20(\mathrm{~T})$ & 6 & PO6 & 4 \\
fir & PU & $60(\mathrm{~W}) \times 30(\mathrm{~T})$ & 4 & DO4 & 5 \\
\hline
\end{tabular}

*: T represents the thickness of laminates. 


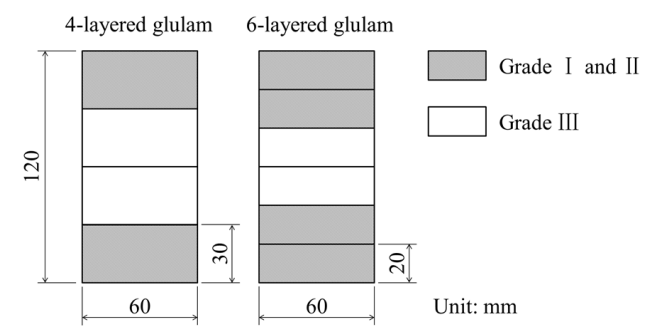

Figure 2. Cross-section of the glulam specimens.

\subsection{Equipment and Experiment}

A four-point load static bending test (i.e., bending test Method A) was performed based on GB/T 26899-2011 at a loading speed of $8 \mathrm{~mm} / \mathrm{min}$. An LVDT (Linear Variable Differential Transformer) sensor was set at the midspan of each specimen. (Figure 3). The MOE for bending and MOR are calculated by the following Equation:

$$
\begin{gathered}
\mathrm{MOE}=\frac{\Delta P(l-s)\left(2 l^{2}+2 l s-s^{2}\right)}{8 \Delta y b h^{3}} \\
\mathrm{MOR}=\frac{3 P_{\max }(l-s)}{2 b h^{2}}
\end{gathered}
$$

where $\Delta P$ is the difference between the upper and lower loads at the proportional limit, $l$ is the span of the specimen between supports, $s$ is the span of the specimen between the loading points, $\Delta y$ is the corresponding midspan deflection of $\Delta P, b$ is the width of the specimen, $h$ is the depth of specimen and $P_{\max }$ is the maximum load.

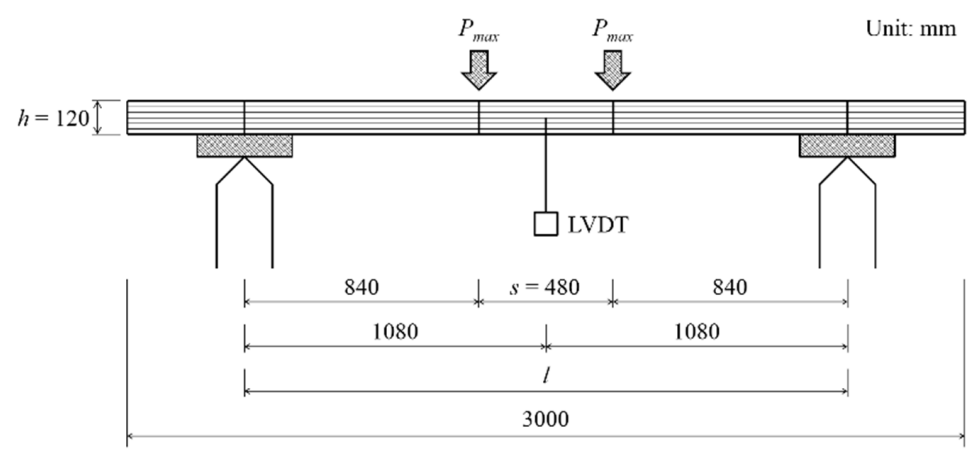

Figure 3. Bending test Method A (side view).

\section{Experimental Results and Discussion}

\subsection{Failure Modes}

Elastic deformation occurred in the specimens during the initial stage of loading. As the load increased, plastic deformation occurred in the specimens. At this stage, many small compression wrinkles appeared in the specimens. The bending rigidity of the specimen decreased marginally, and the deformations increased significantly. Finally, the bottom laminates reached their ultimate tensile stresses. The finger joints of the bottom laminate or defects in the timber failed first, which led to brittle failure of the specimen. The three typical failure modes observed are shown in Figure 4.

The failure modes were connected to the finger joint to some degree. Structural glulam requires a large number of finger joints, so studies of finger joint fatigue strength are very important [23]. There are quite a few research works aimed at the relationship between the bending strength of glulam and finger joint strength. 


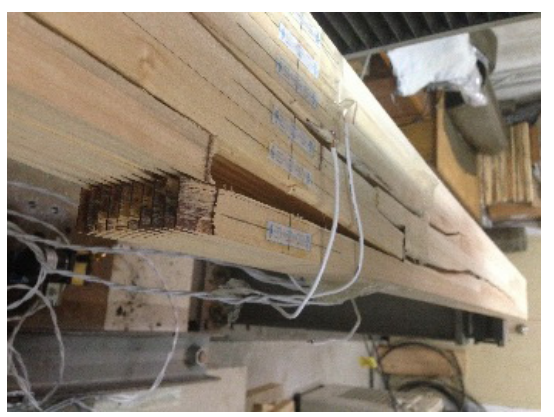

(a)

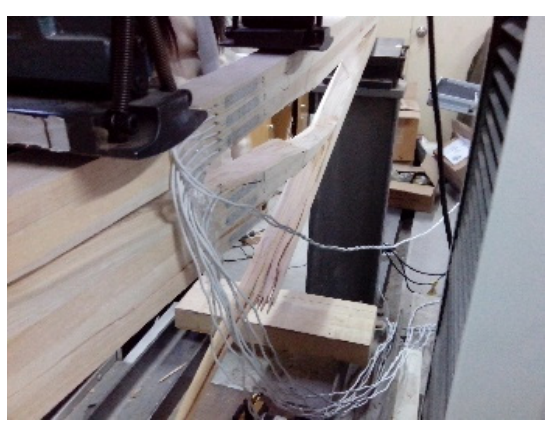

(b)

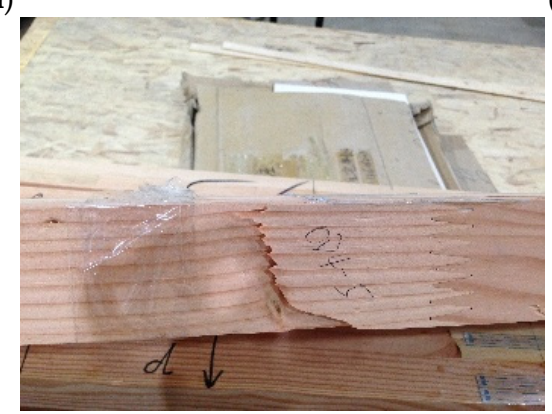

(c)

Figure 4. Typical failure modes of specimens. (a) Shear failure of finger joint (PR4 and PR6); (b) shear failure of finger joint and splitting of timber (PO6); (c) splitting of timber (DO4 and DO6).

In terms of experimental research, Ohuchi [24,25] came to a conclusion based on bending tests of hinoki (Chamaecyparis obtusa) and sugi finger-jointed laminae. In these studies, to examine the optimum adhesive condition in the finger-joint part that influences the strength properties of the large-scale finger-jointed laminae, the block shear tests with block specimens that assumed the finger-joint part and glued under various adhesive conditions was performed. In conclusion, for glulam with good strength properties, the evaluation of finger-joint properties is important. In addition, Frese [26] tested the characteristic bending strength of beech glulam and characteristic finger joint bending strength. The conclusion was proposed that the bending strength of glulam depends on both board strength and finger joint strength.

In terms of the glulam strength model, Frese [11] put forward a glulam model, where its bending strength depends both on the board tensile strength and finger joint tensile strength. This model could determine the influence of the board and finger joint strength on glulam bending strength, which proved the relationship between the bending strength of glulam and finger joint strength. As a result, the poor characteristic bending strength values of the 38 test beams were mainly caused by too low requirements for boards and finger joints, which verified the model. In addition, Frese [10,27] proposed a predictive model for characteristic glulam bending strength based on tension tests of the boards and the finger joints. The experimental values of them were used as input data for the strength models to calculate the predictive values of the glulam. This model predicted the characteristic glulam bending strength precisely. Comparisons between the experimental data and the analytical results from the computer model show a good agreement. The predictive values for the characteristic glulam bending strength and the experimental ones differed not more than $6 \%$. This indicated that the bending strength of glulam was determined by finger joint strength to a large extent.

Therefore, based on the above research, the following conclusions were proposed.

Shear failure of the finger joint led to the failures of PR4 and PR6. The bending strengths of PR4 and PR6 were indicative of the bonding strength of a finger joint with RF, but did not fully describe the mechanical properties of Cathay poplar. 
Shear failure of the finger joint and splitting of timber caused the failure of PO6. The bending strength of PO6 was indicative of both the bonding strength of a finger joint with PU and the mechanical properties of Cathay poplar. Compared to the RF, the Cathay poplar glued with PU performs better.

Splitting of timber resulted in the failures of DO4 and DO6. The bending strengths of DO4 and DO6 were indicative of the mechanical properties of Douglas fir, but did not fully describe the bonding strength of a finger joint with PU.

\subsection{Experimental Results}

The load displacement curves of the mean value of the specimens from each series are shown in Figure 5 as solid lines, and the single results are shown as dotted lines. Compared to the Douglas fir glulam, the Cathay poplar glulam has a lower stiffness, but a slightly higher strength. The PU is shown to be more effective than the RF when used to glue the Cathay poplar glulam specimens. With the same thickness, the strength of the specimen increased when the number of layers increased.

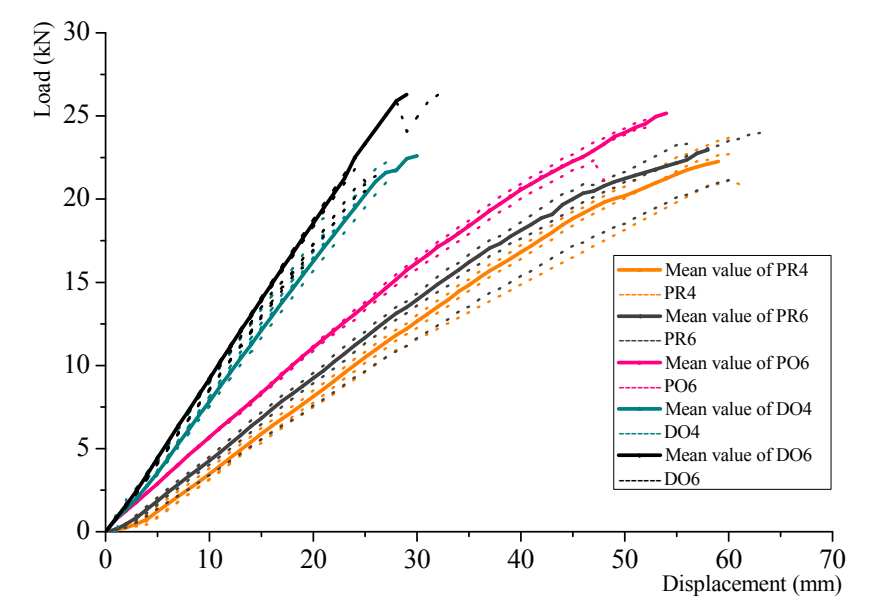

Figure 5. Load displacement curves of mean value of the specimens from each series and single results.

Figure 6 shows the relationship between the MOE and MOR. The mean values of each series are summarized in Table 3. Based on these results, the following conclusions are proposed.

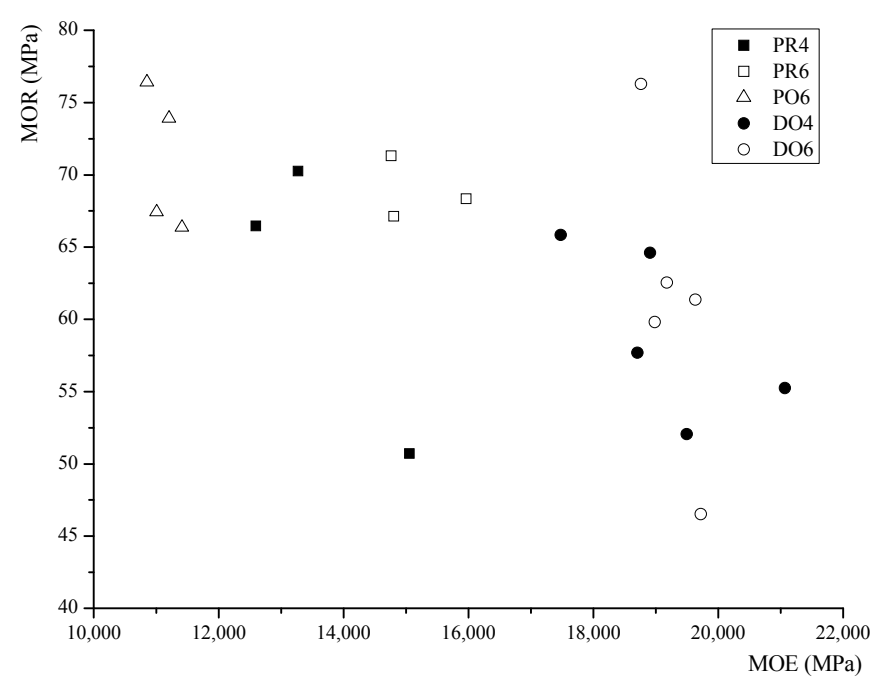

Figure 6. Scatter plot of MOR versus MOE for each series. 
Table 3. Experimental results of each series.

\begin{tabular}{ccccccc}
\hline Specimen & $\begin{array}{c}\text { Maximum Load } \\
\boldsymbol{P}_{\max }(\mathbf{k N})\end{array}$ & $\begin{array}{c}\text { Maximum } \\
\text { Deflection } \mathbf{( m m})\end{array}$ & $\begin{array}{c}\text { MOR } \\
\mathbf{( M P a}\end{array}$ & $\begin{array}{c}\text { MOE } \\
\mathbf{( M P a )}\end{array}$ & $\begin{array}{c}\text { Bending } \\
\text { Rigidity (MPa) }\end{array}$ & $\begin{array}{c}\text { Ultimate } \\
\text { Tensile Strain }\end{array}$ \\
\hline PR4 & 23.24 & 59.67 & 68.37 & 8930 & $77.16 \times 10^{9}$ & 0.0034 \\
PR6 & 23.44 & 58.56 & 69.22 & 9243 & $79.86 \times 10^{9}$ & 0.0047 \\
PO6 & 24.33 & 49.75 & 71.04 & 11,119 & $96.07 \times 10^{9}$ & 0.0053 \\
DO4 & 22.33 & 27.86 & 65.22 & 18,195 & $157.20 \times 10^{9}$ & 0.0032 \\
DO6 & 23.77 & 28.96 & 69.41 & 18,971 & $163.91 \times 10^{9}$ & 0.0038 \\
\hline
\end{tabular}

Firstly, a comparison of the different wood species was performed. The MOR of PR6 was $2.4 \%$ higher than that of DO6, and the MOE of DO6 was 70.6\% higher than that of PO6. In this study, the Cathay poplar glulam had a lower stiffness, but a marginally higher strength compared to those of the Douglas fir glulam. The ultimate tensile strain of PO6 was 0.0053, and the maximum compressive strain was 0.0063 ; these values were both higher than those of Douglas fir glulam.

Secondly, a comparison of the different adhesives was performed. Based on the experimental results, the MOR of PO6 was 2.6\% higher than that of PR6, and the MOE of PR6 was 32.9\% higher than that of PO6. For the Cathay poplar glulam, the PU is shown to be more effective than the RF.

Lastly, a comparison of the different numbers of layers was performed. The MOR of PR6 was $1.2 \%$ higher than that of PR4, and the MOR of DO6 was $6.4 \%$ higher than that of DO4. The MOE of PR6 was $14.3 \%$ higher than that of PR4, and the MOE of DO6 was $4.3 \%$ higher than that of DO4. With the same thickness, the bending strength increased as the number of layers increased.

\subsection{Checking Calculation}

The bending strength, the shear strength and the deflection of the glulam specimens were checked.

The load of a room was assumed to be carried by sample PO6. Based on the characteristic load combination in GB 50009-2012 [28], the design value of the load was $4000 \mathrm{~N}$. According to the four-point load static bending test method, the design value of the maximum moment $M$ and maximum shear strength $V$ were $1.68 \times 10^{6} \mathrm{~N} \cdot \mathrm{mm}$ and $2000 \mathrm{~N}$ based on the principle of the balance of force and moment, respectively. The shear diagram and bending moment diagram are shown as Figure 7.

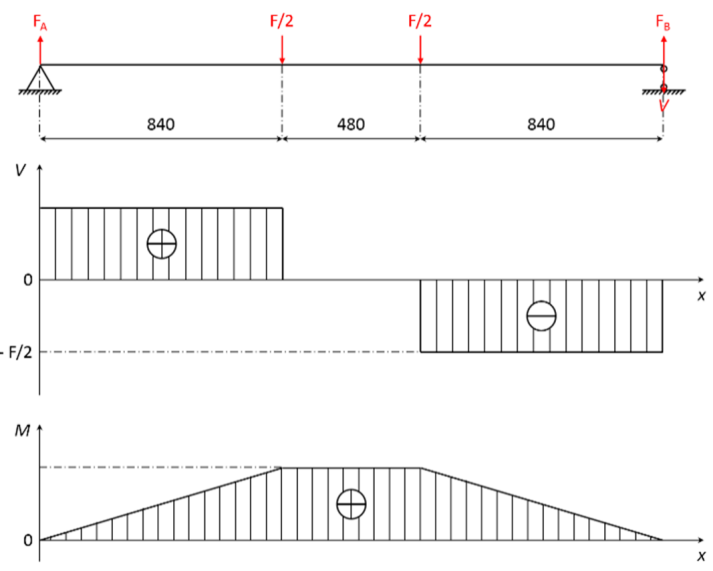

Figure 7. Shear diagram and bending moment diagram.

The characteristic values (i.e., $5 \%$, the percentile of the sample) of the mechanical strength of the Cathay Poplar were calculated. Based on GB 50005-2003 [29], a national standard code for the design of timber structures issued by the Ministry of Housing and Urban-Rural Development of the People's 
Republic of China, the Cathay poplar achieved a strength grade of TB (Tally of Broadleaf tree) 17. As shown in Figure 4.2.1-3 of GB 50005-2003, the wood species that achieved a strength grade of TB17 all have a design bending strength of $17 \mathrm{MPa}$ and a design shear strength parallel to the grain of $2.4 \mathrm{MPa}$. Accordingly, the design values of the bending strength $f_{m}$ and the shear strength parallel to the grain $f_{v}$ were 17 and $2.4 \mathrm{MPa}$, respectively.

\subsubsection{Checking Calculation of the Bending Strength}

The bending strength was checked by Equation (3). $S$ is the section modulus, which was $1.44 \times 10^{5} \mathrm{~mm}^{3}$, and $M$ was $1.68 \times 10^{6} \mathrm{~N} \cdot \mathrm{mm}$.

$$
\frac{M}{S} \leqslant f_{m}
$$

The value of checking calculation was $11.67 \mathrm{MPa}$, which was lower than the design value of bending strength $f_{m}(17 \mathrm{MPa})$. In conclusion, PO6 achieves the required bending strength in GB 50009-2012.

\subsubsection{Checking Calculation of the Horizontal Shearing Strength}

The shearing strength was checked by Equation (4). $Q$ is the first moment of area, which was $1.08 \times 10^{5} \mathrm{~mm}^{3}$; $I$ is the second moment of area (i.e., moment of inertia), which was $8.64 \times 10^{6} \mathrm{~mm}^{4}$; $b$ is the width of the specimen, which was $60 \mathrm{~mm}$; and $V$ was $2000 \mathrm{~N}$.

$$
\frac{V Q}{I b} \leqslant f_{v}
$$

The value of checking calculation was $0.42 \mathrm{MPa}$, which was lower than design value of horizontal shearing strength $f_{m}(2.4 \mathrm{MPa})$. In conclusion, PO6 achieves the required horizontal shearing strength in GB 50009-2012 [28].

\subsubsection{Checking Calculation of the Deflection}

The deflection was checked by Equation (5). $\delta^{\prime}$ is the design value of the deflection, which was $8.64 \mathrm{~mm}$, and $\delta$ is the calculated deflection, which was calculated by Equation (6).

$$
\delta=\frac{F(l-s)\left(2 l^{2}-2 l s-s^{2}\right)}{8 E b h^{3}}
$$

The MOE of PO6 was 11,119 MPa, so the value of checking calculation was $8.14 \mathrm{~mm}$, which was lower than the design value of deflection. In conclusion, PO6 satisfies the deflection requirements in GB 50009-2012 [28].

Therefore, the bending strength, shear strength and deflection of PO6 pass the checking calculations.

\section{Derivations of Formulae}

\subsection{MOE of the Cathay Poplar Glulam}

The MOE for bending of the Cathay poplar glulam was calculated based on that of sawn lumber using a formula that will now be described. The accuracy of the formula is also verified below.

Wang and Chang [30] showed that the strength of laminate was based on the bending stiffness of laminates $\left(e_{j} I_{j}=\right.$ the bending stiffness of the $j$ laminate). The bending stiffness of a glulam specimen was the sum of the bending stiffness of each laminate layer under the non-glued layers, as shown in Equation (7) [31]:

$$
E_{b} I=\sum e_{j} I_{j}
$$


where $E_{b}$ is the MOE of the glulam specimen; $I$ is the section moment of inertia of the glulam specimen; and $e_{j} I_{j}$ is the MOE multiplied by the section moment of inertia of the $j$ laminate $(j=1$, $2,3 \ldots, 6)$, respectively.

Based on the parallel axis theorem from material mechanics [32], the section moment of inertia of laminates can be transformed into the section moment of inertia of the central plane of the glulam specimen as Equation (8):

$$
I_{j}=I_{j}+A_{j}\left(d_{j}\right)^{2}
$$

where $I_{j 0}$ is the section moment of inertia of the $j$-th laminate to the central plane of the glulam specimen; $A_{j}$ is the sectional area of the $j$-th laminate; and $d_{j}$ is the distance between the $j$-th laminate and the central plane of the glulam specimen.

Equation (8) was then substituted into Equation (7):

$$
E=\frac{1}{I} \sum_{j=1}^{n} E_{j}\left[I_{j}+A_{j}\left(d_{j}\right)^{2}\right]
$$

The mean values of the theoretical results of Equation (9) are shown in Table 4. The error between the test and theoretical results of PO6 was $2.89 \%$; thus, the formula predicts the MOE of PO6 accurately. However, the error of PR4 and PR6 is somewhat larger; this is probably because the shear failure of finger joint led to the failures of PR4 and PR6, and thus, the bending properties of PR4 and PR6 did not fully describe the mechanical properties of the Cathay poplar. Therefore, the calculated MOE of PO6 is more precise than that of PR4 and PR6 based on existing data. Moreover, Equation (9) would be validated with more data by further experiments to test its accuracy.

Table 4. MOE of the Cathay poplar glulam from the experimental tests and calculations.

\begin{tabular}{cccc}
\hline Specimen & $\begin{array}{c}\text { Experimental Results } \\
\mathbf{( M P a )}\end{array}$ & $\begin{array}{c}\text { Theoretical Results } \\
\mathbf{( M P a )}\end{array}$ & Error (\%) \\
PR4 & 8930 & 11,113 & 24.4 \\
PR6 & 9243 & 11,441 & 23.8 \\
PO6 & 11,119 & 11,441 & 2.9 \\
\hline
\end{tabular}

\subsection{MOR of the Cathay Poplar Glulam}

The MOR of glulam is typically significantly better compared to that of sawn lumber due to the distribution of defects in the lumber [33]. The MOR of glulam is closely related to its material properties. To explore the relationship between the MOR of glulam and the tensile strength or the MOR of the lumber used, three formulae were derived.

\subsubsection{Equation Referenced EN 1194 [34]}

Based on many experimental results, EN (European Norm) 1194 (Europe Standard Committee) has shown that the relationship between the MOR of the bending of glulam and the tensile strength of the lumber used is linear. A laminate coefficient $\lambda$ is thus introduced and is expressed in the following two Equation:

$$
\begin{aligned}
& f_{b, g l, k}=7.35+1.12 f_{t, l a m, k} \\
& \lambda=1.12+7.35 / f_{t, l a m, k}
\end{aligned}
$$

where $f_{b, g l, k}$ is the characteristic MOR of glulam and $f_{t, l a m, k}$ is the characteristic value of the tensile strength of the lumber.

The laminate coefficient $\lambda$ is inversely proportional to the characteristic value of the tensile strength of the lumber $f_{t, l a m, k}$. For lumber that has higher tensile properties, its laminate coefficient is smaller than lumber that has lower tensile properties. Therefore, the bending properties of glulam made of worse lumber have greatly improved compared to glulam made of better lumber. 
The correlation coefficient $r=0.945$ and the two formulae are only suitable for glulam with a thickness of $600 \mathrm{~mm}$. If the dimensions are different, the MOR should be multiplied by the volume factor $k[35,36]$,

$$
\frac{F_{b}}{F_{b}}=C_{v}=\left(\frac{V}{V}\right)^{k}
$$

where $F_{b}$ is the MOR of glulam with other dimensions, $F_{b 0}$ is the MOR of glulam with standard dimensions, $V_{0}$ is the standard volume $(130 \mathrm{~mm} \times 300 \mathrm{~mm} \times 6400 \mathrm{~mm}), V$ is the measured volume and $k$ is the volume factor $=0.076$ [35].

\subsubsection{Regression Analysis}

Based on the bending and tensile results, regression analysis is used to describe the relationship between the MOR of glulam and the tensile strength of the lumber used. The tensile strengths of the lumber mean the mean experimental values of $20 \mathrm{~mm}$-thick lumber and the mean experimental values of $30 \mathrm{~mm}$-thick lumber. In this formula, the tensile strength of the lumber is an independent variable, and the MOR of glulam is a dependent variable. Based on the scatter diagram drawn by Origin (Figure 8), the relationship appears to be linear.

$$
f_{b, g l, k}=2.22 f_{t, l a m, k}-13.68(\mathrm{R} 2=0.596)
$$

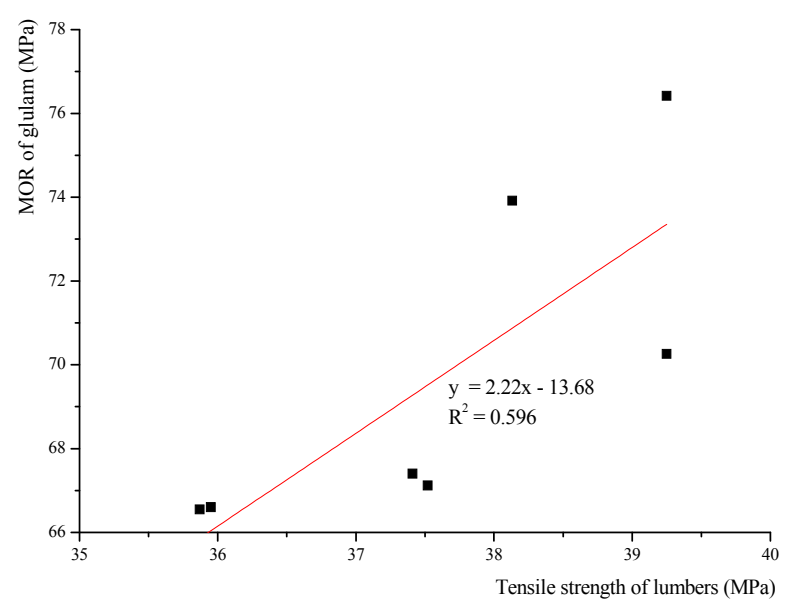

Figure 8. Linear regression analysis of the MOR of glulam.

\subsubsection{Equation Based on the Parallel Axis Theorem}

Equation (14) was derived to describe the relationship between the MOR of glulam and the MOR of the lumber used. For symmetrical glulam, the MOR is expressed by the following Equation:

$$
\sigma=E \varepsilon
$$

where $\sigma$ is the MOR of glulam, $E$ is the MOE for the bending of glulam and $\varepsilon$ is the elongation of a unit length.

Equation (8) in Section 4.1 was substituted into Equation (13) and Equation (14) to derive:

$$
\sigma=\varepsilon \times \frac{1}{I} \sum_{j=1}^{n} E_{j}\left[I_{j}+A_{j}\left(d_{j}\right)^{2}\right]
$$




\subsubsection{Comparison between Test and Theoretical Results}

The mean values of the theoretical results of Equations (10), (12) and (14) are shown in Table 5. In terms of existing data, Equation (12) predicts the MOR well, but the errors of Equations (10) and (14) are somewhat large. Moreover, these three formula would be validated with more data by further experiment to test their accuracy.

Table 5. MOR of Cathay poplar glulam from the test and theoretical results.

\begin{tabular}{cccccccccc}
\hline & & Corrected & \multicolumn{2}{c}{ Equation (10) } & \multicolumn{2}{c}{ Equation (12) } & \multicolumn{2}{c}{ Equation (14) } \\
\cline { 5 - 9 } Specimen & $\begin{array}{c}\text { Experimental } \\
\text { Results (MPa) }\end{array}$ & $\begin{array}{c}\text { Experimental } \\
\text { Results (MPa) }\end{array}$ & $\begin{array}{c}\text { Theoretical } \\
\text { Results } \\
\text { (MPa) }\end{array}$ & $\begin{array}{c}\text { Error } \\
\mathbf{( \% )}\end{array}$ & $\begin{array}{c}\text { Theoretical } \\
\text { Results } \\
\text { (MPa) }\end{array}$ & $\begin{array}{c}\text { Error } \\
\text { (\%) }\end{array}$ & $\begin{array}{c}\text { Theoretical } \\
\text { Results } \\
\text { (MPa) }\end{array}$ & $\begin{array}{c}\text { Error } \\
\text { (\%) }\end{array}$ \\
\hline PR4 & 68.37 & 56.79 & 47.55 & -30.5 & 69.57 & -1.8 & 52.61 & -23.0 \\
PR6 & 69.22 & 57.49 & 51.31 & -25.9 & 70.24 & 1.5 & 76.53 & 10.6 \\
PO6 & 71.04 & 59.01 & 51.31 & -27.8 & 70.24 & -1.2 & 76.53 & 7.7 \\
\hline
\end{tabular}

The theoretical results are shown to be $28.03 \%$ higher than the corrected experimental results on average. This is probably because Equation (10) was derived based on the experimental results of European glulam, and their mechanical properties have many differences from that of Cathay poplar glulam.

Equation (12) was derived based on the experimental results, and the theoretical results are similar to the experimental results. Equation (12) can predict the MOR of Cathay poplar glulam.

Equation (14) shows that the error between the test and calculated values of PR4 is somewhat larger. This is because of the softening of a finger-joint bond. This deviation leads to $23.04 \%$ lower theoretical results compared to the experimental results.

\section{Finite Element Analysis}

The MOE and MOR of Cathay poplar glulam are calculated using the finite element program ANSYS, Version 14.5. Figure 9 shows the meshed finite element model with the loads and constraints. The "8 nodes solid 185" element was chosen, and the material properties were defined based on the experimental results of Cathay poplar glulam. Cathay poplar is orthotropic, and the glue layers (the MOE is $3000 \mathrm{MPa}$, and Poisson's ratio $\mu$ is 0.37 ) are isotropic. Knots were not taken into consideration when the model was established. The compressive zone is assumed to be ideally elastoplastic, and the tensile zone is assumed to be ideally elastic. The calculation does not stop until the tensile stress in the center of an element lies in between a range $\pm 0.5 \%$ of the tensile strength of the board section [10].

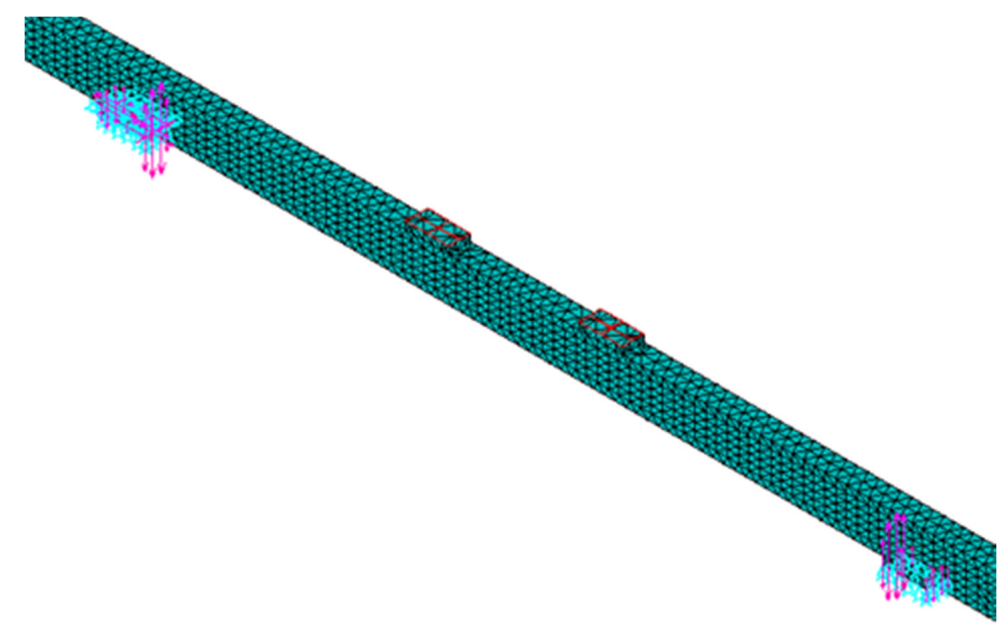

Figure 9. Meshed finite element model with loads and constraints. 
In addition, four elastic cushion blocks are set at two of the supports and two loading points to mitigate stress concentrations and to create a more accurate simulation. Based on He [37] and Tuohuti [38], the elastic cushion blocks are isotropic. The MOE is $1000 \mathrm{MPa}$, and Poisson's ratio $\mu$ is 0.2 .

The mean values of the simulation results of the MOE for bending and MOR of Cathay poplar glulam are shown in Table 6.

Table 6. MOE and MOR of Cathay poplar glulam from the test and simulation results.

\begin{tabular}{ccccccc}
\hline \multirow{2}{*}{ Specimen } & \multicolumn{3}{c}{ MOE } & \multicolumn{3}{c}{ MOR } \\
\cline { 2 - 7 } & $\begin{array}{c}\text { Experimental } \\
\text { Results (MPa) }\end{array}$ & $\begin{array}{c}\text { Simulation } \\
\text { Results (MPa) }\end{array}$ & $\begin{array}{c}\text { Error } \\
\mathbf{( \% )}\end{array}$ & $\begin{array}{c}\text { Experimental } \\
\text { Results (MPa) }\end{array}$ & $\begin{array}{c}\text { Simulation } \\
\text { Results (MPa) }\end{array}$ & $\begin{array}{c}\text { Error } \\
\mathbf{( \% )}\end{array}$ \\
\hline PR4 & 8930 & 9732 & 9.0 & 68.37 & 63.04 & -5.3 \\
PR6 & 9243 & 9952 & 7.7 & 69.22 & 65.49 & -5.4 \\
PO6 & 11,119 & 11,439 & 2.8 & 71.04 & 68.24 & -3.9 \\
\hline
\end{tabular}

For the MOE, the simulation results are all higher than the experimental results. The mean error of PR4 is $8.98 \%$, while that of PR6 is $7.67 \%$; the error of PO6 is lower $(2.79 \%)$. Thus, the simulation of PO6 is more accurate than those of PR4 and PR6.

For the MOR, the simulation results are all lower than the experimental results. The mean error of PR4 is $-5.33 \%$, that of PR6 is $-5.39 \%$ and that of PO6 is $-3.89 \%$. Thus, the simulation of PO6 is more accurate than those of PR4 and PR6.

Therefore, the simulations of the MOE and MOR of PO6 are better than those of PR4 and PR6.

Figure 10a compares the experimental results of the MOE for bending and MOR with the calculation and simulation results.

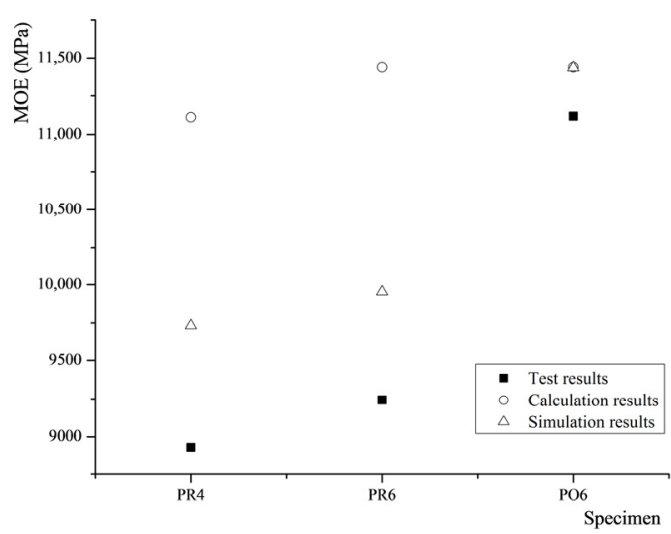

(a)

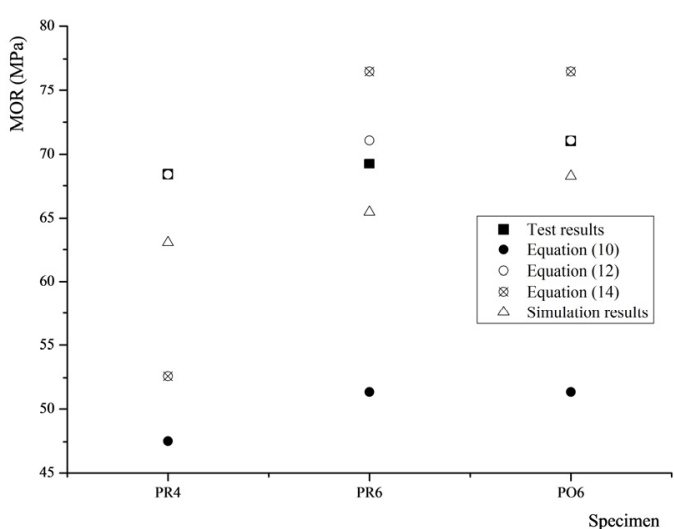

(b)

Figure 10. Experimental results of $\operatorname{MOE}(\mathbf{a})$ and $\mathrm{MOR}(\mathbf{b})$ compared to the calculation and simulation results.

For the MOE, the calculation and simulation results of PO6 approach the experimental results, but the errors between the results of PR4 and PR6 are somewhat larger. Therefore, the formulae and simulation model are both suitable to predict the MOE of Cathay poplar glulam glued with PU.

For the MOR, the error between the test and simulation results is small, but the error between the test and theoretical results is somewhat larger. Therefore, the results of the finite element analysis are more accurate than those of the formulae. This is probably because the glue layers were considered in the simulation models, but the formulae were derived without considering the glue layers. 


\section{Conclusions}

Based on the experiments, calculations and finite element analysis, the following conclusions can be drawn.

Cathay poplar glulam has a lower stiffness, but slightly higher strength compared to Douglas fir glulam in this experiment. The ultimate tensile strain of Cathay poplar glulam glued with polyurethane is 0.0053 , and its maximum compressive strain is 0.0063 , both of which are higher than those of Douglas fir glulam. This study indicates that Cathay poplar has the potential to be glulam material in China. In terms of the adhesive, the MOR of six-layer Cathay poplar glulam glued with one-component polyurethane adhesive is $2.6 \%$ higher than that of six-layer Cathay poplar glulam glued with resorcinol formaldehyde resin adhesive, and the MOE of the latter is $32.9 \%$ higher than that of the former.

A formula is derived to predict the MOE of Cathay poplar glulam based on the MOE of its laminates. The results indicate that the formula could predict the MOE of six-layer Cathay poplar glulam glued with one-component polyurethane adhesive. Three formulae are used to predict the MOR of Cathay poplar glulam based on the MOR and the tensile strength of its laminates. Equation (12) is suitable to predict the MOR of Cathay poplar glulam. The simulation results of both the MOE and MOR of Cathay poplar glulam are similar to the experimental results. The simulation of Cathay poplar glulam glued with one-component polyurethane is shown to be more accurate than those of Cathay poplar glulam glued with resorcinol formaldehyde resin adhesive. The error of the MOE is shown to be $2.8 \%$, and that of the MOR is shown to be $-3.9 \%$.

Acknowledgments: This research work was jointly supported by the Outdoor Wooden Landscape Architecture Materials Properties and Application Research (2015GJ-01) and Research on Chinese Domestic Wood Structure System (K1504003). The authors acknowledge Suzhou Crownhomes Co., Ltd., for providing the experimental equipment and test site. Thanks are given for the tests participation of Yue Yang, Yanfang Fan, Zehua Zhang, Weibo Dong, Zhaoxia Guo, Tingge Yuan and Wanrong Zhu. The authors greatly appreciate the valuable and thoughtful suggestions proposed by the reviewers.

Author Contributions: Ying Gao and Zhiming Yu designed the experiment. Yuxuan Wu, Xudong Zhu and Yong $\mathrm{Wu}$ performed the experiment and analyzed the data. Lei Zhu completed the derivations of the formulae. Yuxuan $\mathrm{Wu}$ prepared and edited the manuscript. Ying Gao reviewed and directed the manuscript.

Conflicts of Interest: The authors declare no conflict of interest.

\section{References}

1. Yang, T.H.; Wang, S.Y.; Lin, C.J. Evaluation of the mechanical properties of Douglas-fir and Japanese cedar lumber and its structural glulam by nondestructive techniques. Constr. Building Mater. 2008, 22, 487-493. [CrossRef]

2. Galligan, W.L.; Snodgrass, D.V.; Crow, G.W. Machine Stress Rating: Practical Concerns for Lumber Producers; U.S.D.A., Forest Products Laboratory, Forest Service: Madison, WI, USA, 1977.

3. He, C.; Zhang, Y. Introduction to gene resources and progress in research on poplars genetic breeding of section tacamahaca in China. J. Northwest For. Univ. 2005, 2, 124-129.

4. Wang, Z.; Fang, Z. Flora Reipublicae Popularis Sinicae; Science Press: Beijing, China, 1984.

5. André, A. Fibres for Strengthening of Timber Structures; Luleå University of Technology: Luleå, Sweden, 2006.

6. Tabiei, A.; Wu, J. Three-dimensional nonlinear orthotropic finite element material model for wood. Compos. Struct. 2000, 5, 143-149. [CrossRef]

7. Moses, D.M.; Prion, H.G.L. Stress and failure analysis of wood composites: a new model. Compos. B Eng. 2004, 35, 251-261. [CrossRef]

8. Serrano, E. Glued-in rods for timber structures-a 3D model and finite element parameter studies. Int. J. Adhes. Adhes. 2001, 21, 115-127. [CrossRef]

9. Gao, Y.; Ohta, M. Deformation analysis of timber-framed panel dome structure I: Simulation of a dome model connected by elastic springs. J. Wood Sci. 2007, 53, 100-107. [CrossRef]

10. Frese, M.; Blaß, H.J. Characteristic bending strength of beech glulam. Mater. Struct. 2007, 40, 3-13. [CrossRef] 
11. Frese, M.; Blaß, H.J. Bending strength of spruce glulam. Eur. J. Wood Wood Prod. 2009, 67, $277-286$. [CrossRef]

12. Frese, M.; Chen, Y.; Blaß, H.J. Tensile strength of spruce glulam. Eur. J. Wood Wood Prod. 2010, 68, $257-265$. [CrossRef]

13. Qiu, L.P.; Zhu, E.C.; van de Kuilen, J.W.G. Modeling crack propagation in wood by extended finite element method. Eur. J. Wood Wood Prod. 2014, 72, 273-283. [CrossRef]

14. Kandler, G.; Füssl, J.; Serrano, E. Effective stiffness prediction of GLT beams based on stiffness distributions of individual lamellas. Wood Sci. Technol. 2015, 1, 1-21. [CrossRef]

15. Kohler, J.; Steiger, R.; Fink, G. Assessment of selected Eurocode based design equations in regard to structural reliability. In Proceedings of the 45th Meeting, International Council for Research and Innovation in Building and Construction, Working Commission W18-Timber Structures, Växjö, Sweden, 27-30 August 2012; Volume 1, pp. 45-102.

16. Fink, G.; Kohler, J. Probabilistic modelling of the tensile related material properties of timber boards and finger joint connections. Eur. J. Wood Wood Prod. 2015, 73, 335-346. [CrossRef]

17. Fink, G.; Kohler, J. Model for the prediction of the tensile strength and tensile stiffness of knot clusters within structural timber. Eur. J. Wood Wood Prod. 2014, 72, 331-341. [CrossRef]

18. Jockwer, R.; Steiger, R.; Frangi, A. Load-carrying capacity and failure modes of glulam beams with reinforced notches. Eur. J. Wood Wood Prod. 2015, 1, 1-2. [CrossRef]

19. Jockwer, R.; Serrano, E.; Gustafsson, P.J. Impact of Growth Characteristics on the Fracture Perpendicular to the Grain of Timber. In Proceedings of the ICASP12-12th International Conference on Applications of Statistics and Probability in Civil Engineering, Vancouver, Canada, 12-15 July 2015.

20. JockwerI, R.; Steiger, R.; Frangi, A. Design of Glulam Beams with Notches at the Support; Eidgenossische Material-Prufungsanstalt: Dübendorf, Switzerland, 2012; Volume 1, pp. 69-74.

21. State Forestry Administration. National Standards of PRC Structural Glued Laminated Timber; Standard No.GB/T 26899-2011. China Standard Press: Beijing, China, 2011.

22. Yamada, M.; Takada, M.; Sano, A. Fire-Resistance Performance of Structural LVL (4). In Abstracts of the 51st Annual Meeting of the Japan Wood Research Society, Tokyo, Japan, 2-4 April 2001; Volume 1, p. 425.

23. Martinez, M.E.; Calil, C.J. Statistical design and orthogonal polynomial model to estimate the tensile fatigue strength of wooden finger joints. Int. J. Fatigue 2003, 25, 237-243. [CrossRef]

24. Ohuchi, T.; Murakami, Y.; Fujimoto, N. Evaluation of finger-jointed laminae for glulam timber by acoustic emission I. Development of jig for acoustic emission sensor installed to production line and its verification test. J. Fac. Agric. Kyushu Univ. 2009, 54, 467-470.

25. Ohuchi, T.; Hermawan, A.; Fujimoto, N. An Experimental Study on Adhesive Condition with Sugi Block Specimen which Assumed Finger-joint by Block Shear Test. J. Fac. Agric. Kyushu Univ. 2013, 58, 99-102.

26. Frese, M.; Blass, H.J. The bending strength of finger joints manufactured from beech wood (Fagus silvatica L.). Holz Als Roh-und Werkstoff 2006, 64, 433-443. [CrossRef]

27. Frese, M.; Hunger, F.; Blaß, H.J.; Glos, P. Validation of strength models for softwood glulam. Eur. J. Wood Wood Prod. 2010, 68, 99-108. [CrossRef]

28. Department of Housing and Urban and Rural Construction. Load Code for the Design of Building Structures; Standard No.GB 50009-2012. China Building Industry Press: Beijing, China, 2012.

29. Ministry of Construction of the People's Republic of China. Code for Design of Timber Structures; Standard No.GB 50005-2003. China Building Industry Press: Beijing, China, 2003.

30. Wang, S.Y.; Chang, T. Studies on the flexural properties of laminated beams with different wood species (1) Bending modulus of elasticity. Q. J. Chin. For. 1978, 11, 43-52.

31. Okuma, M. Studies on the mechanical properties of plywood. Bull. Tokyo Univ. For. 1967, 63, 1-60.

32. Lemaitre, J.; Chaboche, J.L. Mechanics of Solid Materials; Cambridge University Press: Cambridge, UK, 1990.

33. Falk, R.H.; Colling, F. Laminating effects in glued-laminated timber beams. J. Struct. Eng. 1995, 121, 1857-1863. [CrossRef]

34. Timber Structures-Glued Laminated Timber-Strength Classes and Determination of Characteristic Values; Standard No. EN 1194; Sector Committee for Building and Civil Engineering: Bruxelles, Belgium, 1999.

35. Dongmei, J. Study on the Structural Performance of Poplar Glued-Laminated Beams. Master's Thesis, Nanjing University of Technology, Nanjing, China, 2005. 
36. Wolfe, R.W.; Moody, R.C. Bending Strength of Water-Soaked Glued Laminated Beams; Forest Products Lab Madison Wis: Madison, WI, USA, 1978.

37. Feng, H.S.L.L.F.; Pingxiang, C. Finite Element Analysis of Bending Strength for Pinus sylvestris var. mongolica Finger-Jointed Lumber. Sci. Silvae Sin. 2012, 11, 63-68.

38. Tuohuti, A.; Qi, G. Nonlinear analysis of wood beam with software ANSYS. World Earthq. Eng. 2007, 3, 152-157. access article distributed under the terms and conditions of the Creative Commons by Attribution (CC-BY) license (http:// creativecommons.org/licenses/by/4.0/). 